\title{
Mutations affecting germination in Myxococcus xanthus
}

\author{
MontSerrat Elías and Francisco J. Murillo*
}

Departamento de Genética y Microbiología, Facultad de Biología, Universidad de Murcia, 30071 Murcia, Spain (Received 9 May 1990; revised 30 August 1990; accepted 18 October 1990)

\begin{abstract}
Myxococcus xanthus mutants defective in myxospore germination have been isolated both by a selective and by a non-selective method after UV or Tn5-lac-induced mutagenesis. The ability of these mutants to germinate in germinant solutions other than those used for their isolation has been tested. Six of seven mutants isolated behaved as germination-defective in all germinants. Germination of the seventh mutant was conditional on the germinant used, being normal in Casamino acids but defective in a Casitone-based medium. Genetic analysis of the four mutant strains carrying Tn5-lac insertions revealed that the transposon had disrupted a different locus in each mutant, so that the four mutants defined four unlinked loci involved in the germination process $(\operatorname{ger} A, \operatorname{ger} B, \operatorname{ger} C$, gerD). Strain MR307 was studied in more detail. Cloning of the gene affected in this mutant, ger $C$, and construction of merodiploids revealed that the wild-type allele is dominant over the mutated one. In vitro construction of $\operatorname{lac} Z$ fusions allowed study of $\mathrm{ger} C$ expression throughout the $M$. xanthus life cycle, revealing that the gene affected by insertion at $\Omega M R 307$ is developmentally regulated.
\end{abstract}

\section{Introduction}

Myxococcus xanthus is a Gram-negative soil bacterium that undergoes a multicellular cycle of development when subjected to starvation on a solid surface. Vegetative swarms migrate towards centres of aggregation, forming raised mounds of cells (fruiting bodies). Within these mounds individual cells differentiate into spherical, environmentally resistant myxospores. When nutrient limitation ends, germination is triggered and myxospores reconvert to vegetative cells (Zusman, 1984; Dworkin \& Kaiser, 1985). M. xanthus is an excellent bacterial system for the investigation of problems related to the regulation of development (see reviews by Dworkin \& Kaiser, 1985; Shimkets, 1987). Recent development of the necessary genetic tools has allowed identification and cloning of loci associated with fruiting and sporulation (Kaiser, 1984).

We have undertaken the genetic analysis of germination in $M$. xanthus. In an accompanying paper (Elías \& Murillo, 1991) we report a physiological study on germination of wild-type myxospores carried out to facilitate the search for mutants affected in germination. A collection of germination mutants would make it possible to estimate the number of genes involved as well as whether induction by different germinants proceeds through different germination pathways. Here we describe two methods for isolating germination-defective $\left(\mathrm{Ger}^{-}\right)$mutants and report the characterization of several $M$. xanthus mutants. At least four loci affecting myxospore germination have been identified (ger $A$, ger $B$, gerC and ger $D$ ). We also report the cloning of the ger $C$ locus in a vector that replicates in Escherichia coli and the construction of $\mathrm{gerC}^{+} / \mathrm{gerC}^{-}$partial diploids by $\mathrm{Pl}$ specialized transduction (Shimkets et al., 1983) of the chimeric plasmid from $E$. coli to $M$. xanthus.

\section{Methods}

Bacterial strains, phages and plasmids. M. xanthus DK 1050 (RuizVázquez \& Murillo, 1984) was the parental wild-type germinationcompetent $\left(\mathrm{Ger}^{+}\right)$strain. All $\mathrm{Ger}^{-}$mutants were obtained by UV or Tn5-lac mutagenesis of this strain. The symbol $\Omega$ followed by identification letters and numbers is used to denote a transposon insertion site (see Avery \& Kaiser, 1983). In situ replacement of the kanamycin resistance marker $\left(\mathrm{Km}^{\mathrm{R}}\right)$ of $\mathrm{Tn} 5$-lac insertions by oxytetracycline resistance $\left(\mathrm{Tc}^{\mathrm{R}}\right)$ was carried out as described by Avery \& Kaiser (1983).

Phage Mx4-LA27 was used for generalized transduction between $M$. xanthus strains (Avery \& Kaiser, 1983) and coliphage P1 clr-100 cam (Rosner, 1972) was used to transduce cloned DNA from $E$. coli to $M$. xanthus as described by Shimkets et al. (1983).

The cloning vectors pDAH250 and pDAH160 derive from pREG429, a plasmid that carries the $\mathrm{Km}^{\mathrm{R}}$ gene and most of the IS $50 \mathrm{~L}$ element of Tn5, and a DNA fragment encoding P1-specific incompatibility to efficiently transfer the plasmid by $P 1$ specialized transduction (Gill et al. , 1988). Plasmid pDAH156 was used for in vitro construction of $l a c Z$ fusions. The three plasmids were constructed and kindly provided by D. A. Hodgson, University of Warwick, UK.

Culture conditions and preparation of myxospores. M. xanthus was grown vegetatively in CTT broth (Hodgkin \& Kaiser, 1977). Media derived from CTT by lowering the concentration of Bacto-Casitone are referred to as $1 / n$ CTT, where $1 / n$ represents the fraction of Bacto- 


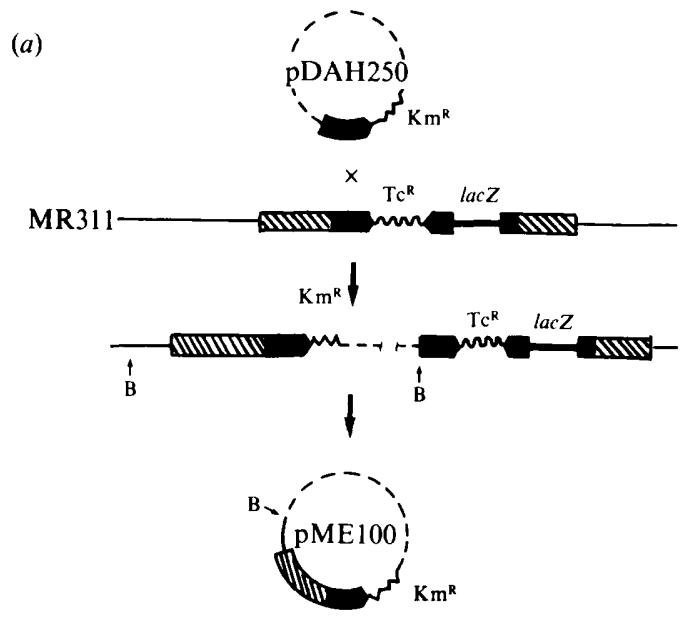

(b)
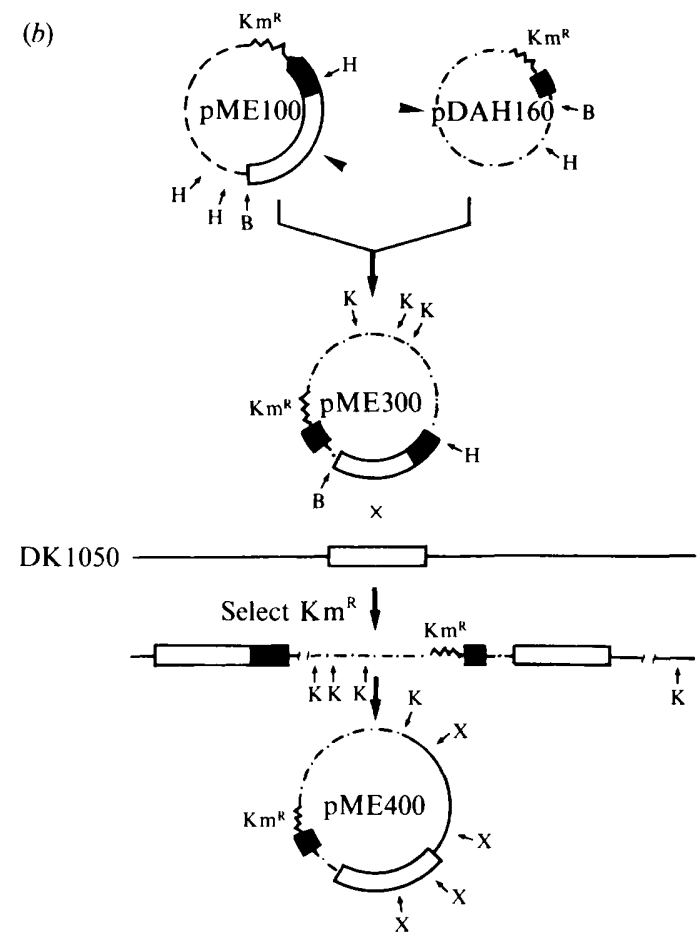

Fig. 1. Cloning of the gerC locus. (a) MR311 is a $\mathrm{Tc}^{\mathrm{R}}$ replacement of strain MR307, which contains a Tn5-lac insertion in gene gerC (hatched box). The vector pDAH250 was transduced into MR311 and $\mathrm{Km}^{\mathrm{R}}$ was selected. Transductants result from integration of the plasmid by homologous recombination between the $1 \mathrm{~S} 50$ sequence (filled box) in pDAH 250 and either the IS 50 left or IS 50 right sequences of the transposon. Integrative recombination into the IS50 right is illustrated. Plasmid pME100, carrying a $4.4 \mathrm{~kb}$ segment of $M$. xanthus DNA adjacent to the IS50 right at $\Omega$ MR307, was obtained after BamHI digestion of chromosomal DNA from a $\mathrm{Km}^{\mathrm{R}} \mathrm{Tc}^{\mathrm{R}}$ transductant and intramolecular ligation. (b) The vector pDAH 160 was used for cloning the complete gerC locus. A $5.4 \mathrm{~kb}$ HindIII-BamHI fragment from pME100 was ligated into a $11.2 \mathrm{~kb}$ fragment from $\operatorname{HindIII/BamHI}$ digested pDAH160 (both fragments are indicated by arrowheads) to generate the $16.7 \mathrm{~kb}$ plasmid pME300, which contains the chromosomal DNA in pME100 (open box) in reversed orientation with respect to
Casitone in the medium with respect to that in CTT $\left(10 \mathrm{mg} \mathrm{ml}^{-1}\right)$. Development was induced on CF agar plates (Hagen et al., 1978). Clonal fruiting bodies for germination analysis were obtained by plating single cells on $\mathrm{CF}$ agar. Fruiting bodies from which myxospores were harvested were obtained from drops of liquid cultures placed on $\mathrm{CF}$ agar. Myxospore suspensions were obtained after sonic disruption of collected fruiting bodies (for details, see Elías \& Murillo, 1991).

Mutagenesis and mutant isolation. UV mutagenesis was carried out by exposing $3 \mathrm{ml}$ of an exponential culture (at a cell density of $10^{8}$ cells $\mathrm{ml}^{-1}$ ) of DK 1050 in CTT broth to irradiation for $90 \mathrm{~min}$ with a germicidal lamp (General Electric, GI5T8), a treatment that yielded around $5 \%$ survival. Cells were then pelleted by centrifugation $(3000 \mathrm{~g}$, $10 \mathrm{~min}$ ), suspended in fresh CTT broth and allowed to grow overnight before plating on CF agar. For Tn5-lac mutagenesis, strain DK 1050 was infected with $\mathrm{PI}:$ : $\mathrm{Tn}$ 5-lac and $\mathrm{Km}^{\mathrm{R}}$ transductants were selected as described by Kroos \& Kaiser (1984).

Germination-defective mutants were isolated by two methods. The first method allows screening for mutants directly on CF agar. Single cells were plated on CF agar, where they first formed colonies and then fruiting bodies. Plates containing clonal fruiting bodies were incubated at $50{ }^{\circ} \mathrm{C}$ for $90 \mathrm{~min}$ to kill vegetative cells and then each plate was overlaid with $10 \mathrm{ml} 1 / 3 \mathrm{CTT}$ soft agar. After incubation at $33^{\circ} \mathrm{C}$ for $24 \mathrm{~h}$, a clone defective for germination among several wild-type clones was easily recognized as showing much less growth or no growth at all. Putative $\mathrm{Ger}^{-}$clones were toothpicked on to CTT plates and those that grew on this medium were tested again for ability to germinate.

In the second method, myxospores were incubated in a germinant solution $\left(2 \mathrm{~g}\right.$ Casamino acids $\mathrm{l}^{-1}$ or $\left.1 / 30 \mathrm{CTT}\right)$ for $24 \mathrm{~h}$, which is long enough to ensure germination of wild-type spores, and selection against germinated cells was performed at $50^{\circ} \mathrm{C}$ for $90 \mathrm{~min}$. Then germination and growth in CTT was allowed. Conditional $\mathrm{Ger}^{-}$mutants were isolated after two cycles of selection.

Expression of $\beta$-galactosidase. Rapid determination of $\beta$-galactosidase production during growth and development was carried out by examining colony colour on CTT plates containing $40 \mu \mathrm{g}$ 5-bromo-4chloro-3-indolyl $\beta$-D-galactoside (X-Gal) $\mathrm{ml}^{-1}$ (CFT X-Gal) and on CF plates containing $20 \mu \mathrm{g} \mathrm{X}-\mathrm{Gal} \mathrm{ml^{-1 }}$ (CF X-Gal).

Disruption of vegetative cells by sonication and measurement of specific $\beta$-galactosidase activity were carried out as previously described (Balsalobre et al., 1987). To assay activity from latedevelopmental or germinating samples, which contain sonicationresistant cell forms, the sonic treatment was performed in the presence of $0.25 \mathrm{~mm}$ glass beads ( 1 vol. beads per 3 vols cell suspension). The cell debris and glass beads were pelleted before activity of $\beta$-galactosidase was determined. Units of $\beta$-galactosidase specific activity are nmol $o$ nitrophenol (ONP) produced $\mathrm{min}^{-1}$ (mg protein) ${ }^{-1}$.

Cloning of the gerC locus. The cloning procedure is illustrated in Fig. 1. Vector pDAH250 was used to construct the $16.1 \mathrm{~kb}$ chimeric plasmid pME100, following the cloning strategy designed by Gill et al. (1988) and illustrated in Fig. 1(a). Plasmid pME100 carries a $4.4 \mathrm{~kb}$ BamHI fragment adjacent to the right IS50 element at $\Omega$ MR307. The complete gene was cloned using vector pDAH160, kindly provided by D. A. Hodgson. This plasmid was designed to enable cloning of $M$. xanthus DNA previously cloned in pDAH250 in reversed orientation with respect to the $\mathrm{Km}^{\mathrm{R}}$ gene. As shown in Fig. l(b), plasmids pDAH160

the $\mathrm{Km}^{\mathrm{R}}$ marker. Plasmid pME300 was transduced into DK 1050 with selection for $\mathrm{Km}^{\mathrm{R}}$ and, after $\mathrm{KpnI}$ digestion and transformation of $E$. coli, the chimeric plasmid pME400 was obtained. This plasmid contained, in addition to the $4.4 \mathrm{~kb}$ segment previously cloned in pME100, $6.6 \mathrm{~kb}$ of chromosomal DNA (thin line) to the right of SMR307. B, H, K and $\mathrm{X}$ are abbreviations for restriction enzymes BamHI, HindIII, KpnI and XhoI, respectively. 

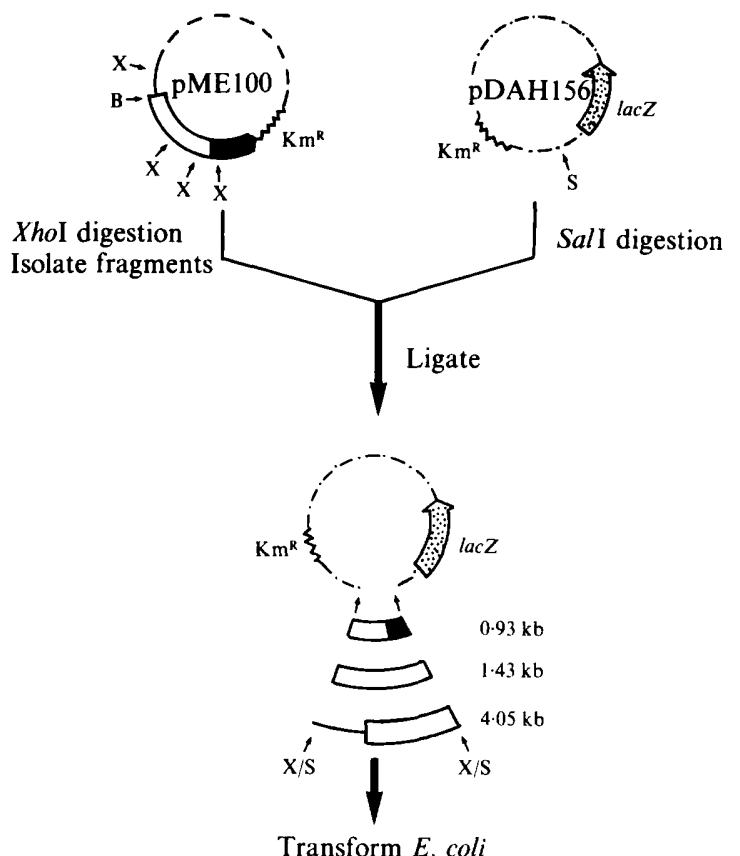

Fig. 2. Construction of in vitro lac $Z$ fusions. The three $X h o l$ fragments (A, $0.93 \mathrm{~kb} ; \mathrm{B}, 1.43 \mathrm{kbi}$; C, $4.05 \mathrm{~kb}$ ) from pME100 containing chromosomal DNA (open box) were isolated and independently ligated into Sall-cut pDAH156. The fragments are in this way inserted upstream of a promoterless lacZ gene (stippled box) and their promoting activity can be tested. Ligation of the fragments in the correct orientation is shown; insertion could equally take place in the opposite orientation. S, Sall; other abbreviations as in Fig. 1.

and pME100 were double digested with HindIII and BamHI, and the resulting fragments were separated by electrophoresis on low-meltingtemperature agarose. The two indicated fragments were extracted from the gel as described by Maniatis et al. (1982) and ligated with T4 DNA ligase (Boehringer Mannheim). The ligation was used to transform $E$. coli MCl061 (Casadaban \& Cohen, 1980) to $\mathrm{Km}^{\mathrm{R}}$ according to Maniatis et al. (1982).

After checking that individual $\mathrm{Km}^{\mathrm{R}}$ transformants carried the desired $16.7 \mathrm{~kb}$ construction (pME300), plasmid DNA in E. coli was introduced into $M$. xanthus DK 1050 by $\mathrm{P} 1$ specialized transduction with selection for $\mathrm{Km}^{\mathrm{R}}$ (Shimkets et al., 1983). The chimeric plasmid pME300 fails to replicate in $M$. xanthus but can integrate by a single homologous recombination event anywhere within its inserted DNA. Chromosomal DNA was extracted (Yee \& lnouye, 1981) from one $\mathrm{Km}^{\mathrm{R}}$ transductant, digested with $K p n I$ and ligated at low DNA concentration (1-5 ug ml-1) to favour circularization rather than polymerization (Stephens \& Kaiser, 1987). Note that $K p n I$ has no restriction site in $M$. xanthus DNA in pME300 and that the distribution of $K p n I$ sites in the vector DNA is such that cloning in the desired direction is possible. The ligation was transformed into $E$. coli $\mathrm{MC} 1061$ with selection for $\mathrm{Km}^{\mathrm{R}}$. The resulting $17 \mathrm{~kb}$ chimeric plasmid (pME400), which carries $11 \mathrm{~kb}$ of cloned DNA, was transferred into $M$. xanthus MR311 by the coliphage P1 and individual $\mathrm{Km}^{\mathrm{R}}$ transductants were tested for their ability to germinate.

Construction of in vitro lac $Z$ fusions. Expression of the gerC locus was studied using the strategy in Fig. 2. Plasmid pDAH156, the vector used for construction of in vitro lac $Z$ fusions, carries a promoterless $l a c Z$ gene located immediately downstream of the unique $\mathrm{Sall}$ site. The chimeric plasmid pME100 was treated with $X h o I$ and the four DNA fragments (A, B, C, D) obtained were electrophoresed on low-melting-temperature agarose. The three fragments containing $M$. xanthus DNA, fragments $A(0.93 \mathrm{~kb}), B(1.43 \mathrm{~kb})$ and $C(4.05 \mathrm{~kb})$, were purified from the gel and separately ligated to $S a \Pi$ linearized pDAH 156 (Maniatis $e t$ al. , 1982). The ligations were used to transform E. coli MC1061 to $\mathrm{Km}^{\mathbb{R}}$. Stocks of $\mathrm{Pl}$ grown on individual $\mathrm{Km}^{\mathrm{R}}$ transformants carrying the desired chimeric plasmids were used separately to transduce $M$. xanthus DK1050 with selection for $\mathrm{Km}^{\mathrm{R}}$.

\section{Results and Discussion}

\section{Isolation of $\mathrm{Ger}^{-}$mutants by the in situ assay}

An in situ assay has been developed to screen for germination-defective mutants directly on CF plates. Basically, spores developed on CF are induced to germinate by overlaying the plates with $1 / 3$ CTT soft agar. This particular concentration was the lowest concentration of Bacto-Casitone that induced in situ germination of the wild-type and at the same time supported growth of the germinated cells. Following this procedure we isolated six $\mathrm{Ger}^{-}$mutants. Four (MR303MR306) were obtained after UV irradiation and screening of 4000 spore-containing colonies. The other two mutants, MR301 and MR302, were obtained following Tn5-lac mutagenesis and screening $2000 \mathrm{Km}^{\mathrm{R}}$ colonies.

The ability of these mutants to germinate in CTT, 1/4 CTT, 1/10 CTT and 1/30 CTT was quantitatively compared to that of the parental strain DK1050. Germination of strains MR301-MR306 was hardly defective in CTT, but as the concentration of Casitone in the germinant solution was decreased the $\mathrm{Ger}^{-}$phenotype became evident. Germination of strains MR303MR306 in 1/30 CTT was followed by microscopic observation and by the loss of heat resistance (Fig. 3). The four mutants germinated poorly at this concentration of Casitone. After $14 \mathrm{~h}$ incubation in 1/30 CTT (long enough to observe complete germination of wild-type spores), $75-95 \%$ of the spore population for the mutant strains was still refractile and round (Fig. $3 a$ ). The germination-defective phenotype was also conspicuous when the germination kinetics were estimated as a percentage of heat-sensitive spores (Fig. $3 b$ ). As shown for the parental strain (Elías \& Murillo, 1991), loss of heat resistance of MR303-MR306 spores occurred much faster than germination assayed by microscopic observation. Strains MR301 and MR302 behaved in a similar way (data not shown).

The six mutants were tested for their ability to germinate in Casamino acids $\left(2 \mathrm{~g} \mathrm{l}^{-1}\right)$ and some defined mixtures of amino acids, previously found to permit germination of wild-type myxospores (Elías \& Murillo, 


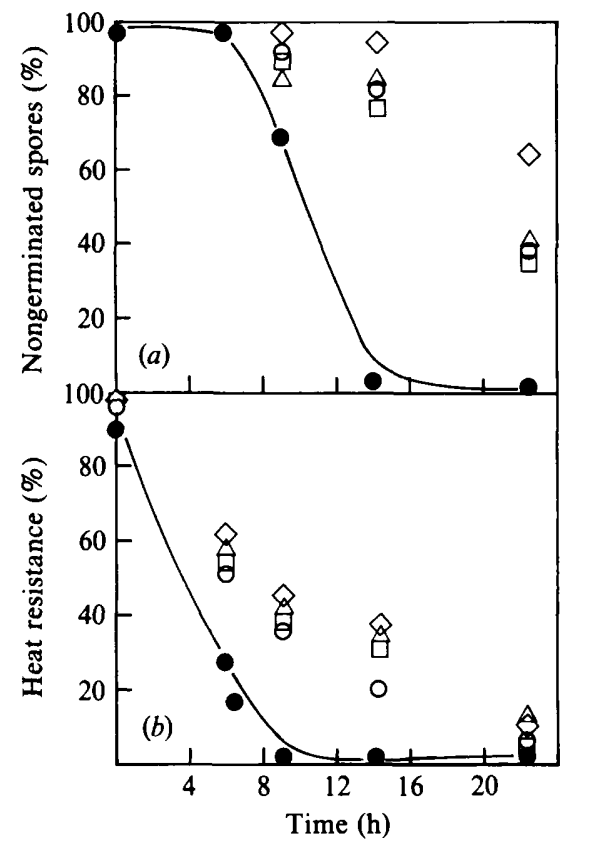

Fig. 3. Germination of the mutant strains MR303 (O), MR304 ( $\square$ ), MR305 $(\triangle)$, and MR306 $(\diamond)$ in 1/30 CTT. Comparison can be made with the germination curve for the wild-type strain DK1050 (O). (a) Loss of refractility and spherical morphology. (b) Loss of heat resistance.

1991). All of them showed defective germination behaviour in these solutions.

The specific defect that causes this generalized $\mathrm{Ger}^{-}$ phenotype has not yet been characterized. Growth rate and plating efficiency both in CTT and in minimal medium (Bretscher \& Kaiser, 1978) for all six mutants was the same as for the wild-type, so a general metabolic defect or an auxotrophy seems unlikely. Under the light microscope, the mutant myxospores appear normal as far as refractility, shape and size are concerned, and fruiting follows the normal course.

The $\mathrm{Km}^{\mathrm{R}}$ determinant at $\mathrm{Tn} 5$-lac insertion sites SMR301 and SMR302 provides a useful genetic marker for transductional analysis. The $\mathrm{Km}^{\mathrm{R}}$ at $\Omega \mathrm{MR} 301$ and SMR302 was separately transduced into the parental strain DK 1050. In both cases, 40 transductants were tested by the in situ assay and they all showed the same $\mathrm{Ger}^{-}$phenotype as the corresponding donor strain. This confirms that the germination defect in strains MR301 and MR302 is the result of an insertional mutation. To study linkage between the two insertions, a cross using MR301 as donor and a $\mathrm{Tc}^{\mathrm{R}}$ replacement of MR302 as recipient was performed. No $\mathrm{Km}^{\mathrm{R}} \mathrm{Tc}^{\mathrm{S}}$ transductants were found among $300 \mathrm{Km}^{\mathrm{R}}$ colonies tested, thus indicating that the Tn5-lac insertion sites involved map at different positions on the chromosome. The genes affected by the transposon insertion at $\Omega M R 301$ and

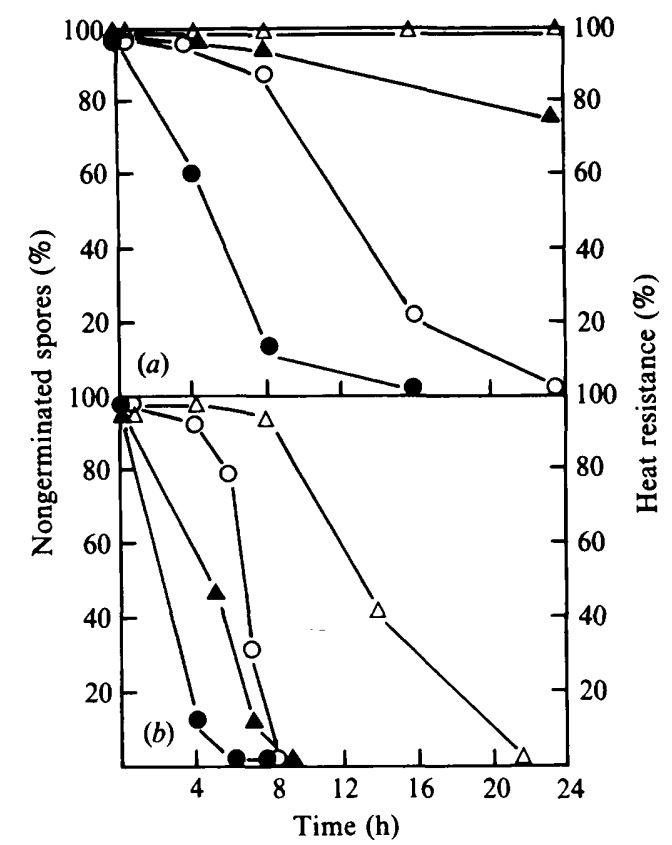

Fig. 4. Ability to germinate $(O, \triangle)$ and loss of heat resistance $(O, \Delta)$ of mutant strain MR307 $(\triangle, \Delta)$ and wild-type strain DK1050 $(O, \odot)$ in Casamino acids $(a)$ and CTT $(b)$.

SMR302 have been designated ger $A$ and $\operatorname{ger} B$, respectively.

Transposon Tn5-lac, constructed by inserting a promoterless trp-lac fusion fragment near the left end of Tn5, was designed to make transcriptional fusions to exogenous promoters (Kroos \& Kaiser, 1984). Expression of the lac $Z$ gene from a Tn5-lac insertion can be readily assayed by measuring $\beta$-galactosidase. To study the regulation of the genes $\operatorname{ger} A$ and $\operatorname{ger} B, \beta$-galactosidase activity was determined for strains MR301 and MR302 during vegetative growth, development and germination. Very low specific activity of $\beta$-galactosidase was found throughout the life cycle for both strains, as would be expected if Tn5-lac had inserted in the wrong orientation to make a fusion.

\section{Isolation of Ger- mutants by a selective procedure}

A selective method for isolating germination mutants was developed based on the possibility of selecting ungerminated spores, which are heat-resistant, from spores that have germinated successfully. Two mutant strains, MR307 and MR308, were independently isolated after insertional mutagenesis with Tn5-lac and two cycles of selection.

Strain MR307 was selected as being incapable of germinating in Casamino acids $\left(2 \mathrm{~g} \mathrm{l}^{-1}\right)$ but still responsive to CTT. Germination of MR307 in Casamino acids $\left(2 \mathrm{~g} \mathrm{l}^{-1}\right)$ and in CTT was quantified microscopically and by the loss of heat resistance and compared with the germination of the wild-type strain DK1050 (Fig. 4). In 

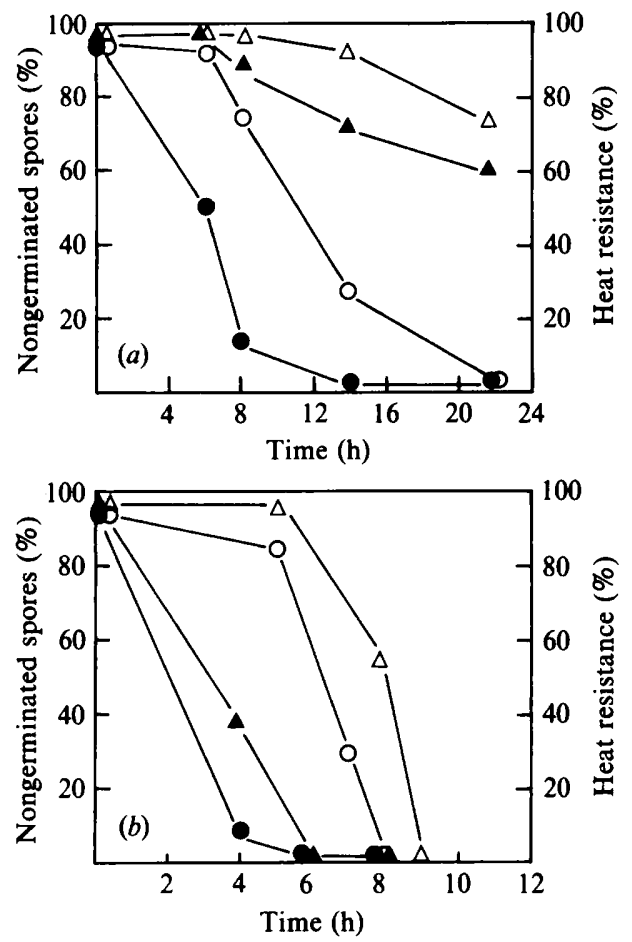

Fig. 5. Ability to germinate $(0, \triangle)$ and loss of heat resistance $(0, \triangle)$ of mutant strain MR308 $(\triangle, \Delta)$ and wild-type strain DK1050 $(O, O)$ in $1 / 30$ CTT $(a)$ and CTT $(b)$.

Casamino acids, no myxospore germination was observed up to $24 \mathrm{~h}$. As expected, given the method used for isolation, the loss of heat resistance after such prolonged incubation was hardly appreciable (Fig. 4a). In CTT, spores of MR307 germinated more slowly than the wildtype. This defective response was particularly clear when germination was followed microscopically (Fig. $4 b$ ). In addition, MR307 failed to germinate in 1/30 CTT, in a mixture of lysine and histidine (each $1 \mathrm{~g} \mathrm{l}^{-1}$ ) which induces germination of the wild-type strain (see Elias \& Murillo, 1991), and at higher or lower concentrations of Casamino acids than $2 \mathrm{~g} \mathrm{l}^{-1}\left(0 \cdot 5-10 \mathrm{~g} \mathrm{l}^{-1}\right)$.

The other mutant, MR308, was selected to show an altered response for germination in 1/30 CTT but not in CTT. We compared germination of MR308 in each germinant solution with germination of DK 1050 (Fig. 5). MR308 was almost as responsive to CTT as the parental strain, when germination was assayed either microscopically or by the loss of heat resistance (Fig. $5 b$ ). In 1/30 CTT, spores of strain MR308 germinated considerably more slowly than spores of DK 1050 . After $24 \mathrm{~h}$ incubation, $60 \%$ of the mutant spores were still heatresistant and around $80 \%$ had not yet shown any visible morphological changes (Fig. 5a). The germination efficiency of MR308 spores dropped rapidly as the concentration of Casitone was progressively lowered from CTT to 1/30 CTT (not shown). For germination in Casamino acids, however, MR308 showed a behaviour close to the wild-type (not shown). The fact that germination of MR308 is conditional on the germinant used might mean that spores of $M$. xanthus have germination-specific reception systems that can be affected independently, or that different germination pathways exist. Consequently, strain MR307 and the six mutants isolated by the preceding method (MR301MR306), all defective for germination in CTT and Casamino acids, might be affected in a gene whose function is common to both reception/germination pathways. Alternatively, their mutant phenotype might be indirectly related to germination and be the consequence, for example, of alterations in the spore structure that supports the germination mechanism.

The only alteration so far detected for mutant strains MR307 and MR308 is at the level of germination. Loss of heat resistance is one of the first events during germination (Elias \& Murillo, 1991). Spores of MR307 and MR308 remain heat-resistant after prolonged incubation in Casamino acids and $1 / 30 \mathrm{CTT}$, respectively. This behaviour, for which they were selected, indicates that both mutants are blocked at an early stage of germination.

Crosses between the mutants and the parental strain were carried out to confirm that their germination behaviour was due to an insertional mutation. The possibility that these two new mutations mapped within one of the previously identified loci or were linked to each other was also studied. Analysis of the antibiotic resistances of 300 transductants from a cross between MR307 and a Tc ${ }^{\mathrm{R}}$ replacement of MR308 revealed that Tn5-lac insertions $\Omega M R 307$ and $\Omega$ MR308 are located in separate unlinked loci. Neither did we find linkage between these mutations and genes ger $A$ and ger $B$. The genes affected by insertion of Tn5-lac at $\Omega$ MR307 and $\Omega$ MR308 have been called ger $C$ and gerD, respectively. The germination mutants isolated to date are therefore not clustered and represent at least four different loci.

Expression of $\beta$-galactosidase was measured for MR307 and MR308 during vegetative growth, development and germination (Fig. 6). Specific activity of $\beta$ galactosidase remained very low for all samples of strain MR307, probably due to the insertion of Tn5-lac in the wrong orientation to allow fusion of lac $Z$ expression to the corresponding promoter. Strain MR308 showed a gradual increase of $\beta$-galactosidase activity during vegetative growth. When induced to develop, expression of $\beta$-galactosidase in MR308 was still high a few hours after cells were spotted on CF medium, though lower than at $t=0$, and continued decreasing throughout development. During germination, $\beta$-galactosidase activity remained constant at around 10 units, which is late 


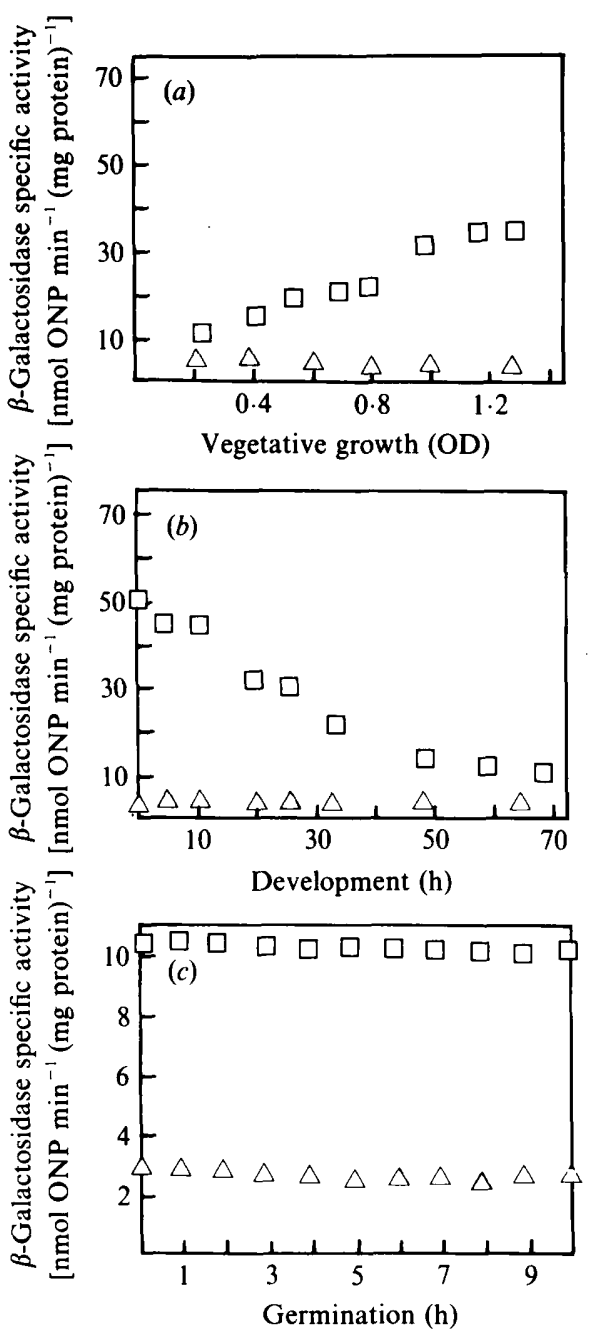

Fig. 6. Expression of $\beta$-galactosidase during vegetative growth $(a)$, development $(b)$ and germination $(c)$ of strains MR307 $\triangle$ ) and MR308 $(\square)$.

similar to the level found at early exponential growth and late development. Thus, insertion of Tn5-lac at $\Omega$ MR308 is affecting a gene that is expressed throughout the $M$. xanthus life cycle, showing maximal levels of expression during late exponential growth and early development. These expression profiles would agree with any of the alternative explanations proposed to account for its particular $\mathrm{Ger}^{-}$phenotype.

\section{Cloning the gerC locus}

Among the mutants isolated, MR307 showed the strongest $\mathrm{Ger}^{-}$phenotype. As a step towards the investigation of the function of the affected locus in germination, we cloned the $\mathrm{gerC}^{+}$allele. Because the mutation in MR307 results from disruption of the gene gerC by insertion of Tn5-lac, a two-step procedure was necessary to clone the wild-type allele. First, the chimeric plasmid pME100 was constructed, according to the

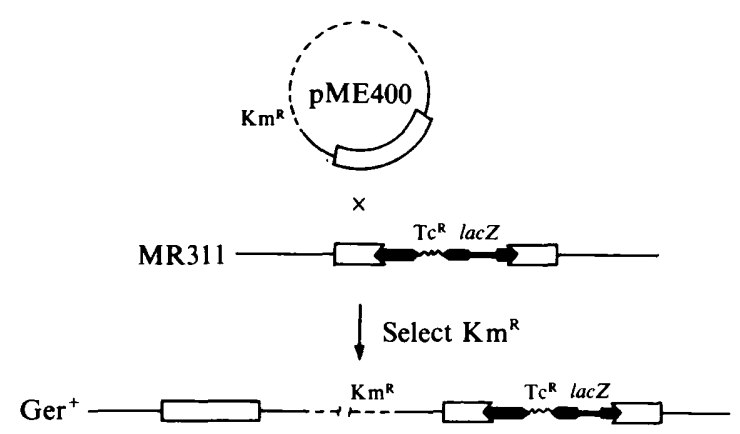

Fig. 7. Construction of partial diploids for $\operatorname{gerC}$. The limits of $\mathrm{gerC}$ (open box) have been arbitrarily drawn. Plasmid pME400 was introduced into strain MR311, which carries an insertional mutation at gerC. Integration of the plasmid by homologous recombination generated $\mathrm{Km}^{\mathrm{R}}$ transductants carrying a wild-type gerC allele and the mutated allele originally present in the recipient strain.

cloning strategy described by Gill et al. (1988). This plasmid carried a $4.4 \mathrm{~kb}$ Bam HI fragment flanking SMR307, and presumably a truncated gerC allele (Fig. $1 a)$. Cloning of the full-length allele was then attempted following the procedure depicted in Fig. 1(b) (see Methods). Taking advantage of sequence homology provided by pME100, a new chimeric plasmid (pME400) was constructed. This plasmid carried an $11 \mathrm{~kb}$ BamHI $K p n I$ fragment spanning $4.4 \mathrm{~kb}$ on one side of $\Omega$ MR307 and $6.6 \mathrm{~kb}$ on the other, and was therefore very likely to include the complete ger $C$ locus.

To verify that pME400 carries the $\operatorname{ger} C^{+}$allele, the plasmid was transduced from $E$. coli to $M$. xanthus MR311 selecting for $\mathrm{Km}^{\mathrm{R}}$, and rescue of the germination defect was determined. If pME400 carried the complete gerC locus, integration of the plasmid would generate a duplication with a wild-type gerC allele on one copy of the duplication and a mutant allele on the other (see Fig. 7). Germination of $14 \mathrm{Km}^{\mathrm{R}} \mathrm{Tc}^{\mathrm{R}}$ transductants in Casamino acids and CTT was tested. Plasmid pME400 restored germination in four such transductants, indicating that pME400 carries the gerC locus and that the $\mathrm{gerC}^{+}$allele is dominant over the mutant allele. Those transductants expected to have the same $\operatorname{gerC}^{+} /$gerC $^{-}$ duplication that, however, showed a defective phenotype, probably arose by gene conversion resulting in two identical mutant alleles. High gene conversion frequencies in $M$. xanthus have also been observed by other groups of workers (Shimkets et al., 1983; Stephens \& Kaiser, 1987), even for mutations caused by a transposon insertion (M. Fontes, personal communication).

Construction of in vitro lac $Z$ fusions to study expression of the gerC gene

Because insertion of Tn5-lac at $\Omega$ MR307 seems to have occurred in the wrong orientation to make a fusion, expression of the gerC gene was determined using a 


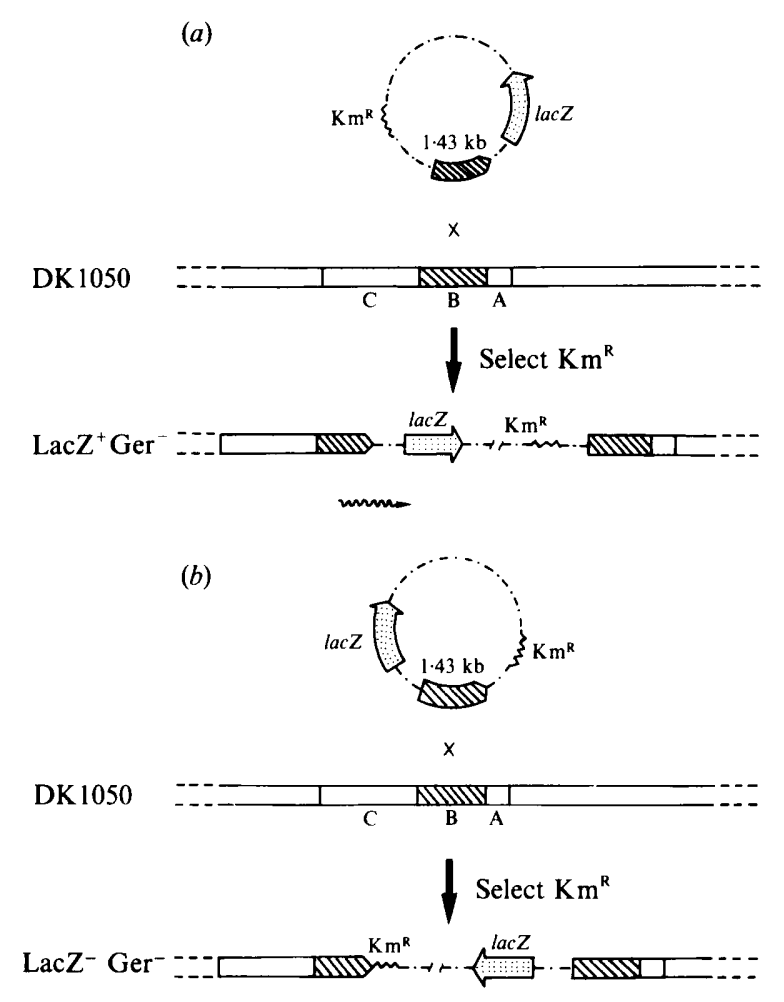

Fig. 8. Introduction into DK 1050 of plasmids carrying $X$ hoI fragment B from pME100 in the correct $(a)$ and in the wrong $(b)$ orientation to make a fusion. Both types of plasmids were constructed following the procedure illustrated in Fig. 2. The relative location in DK1050 of chromosomal DNA in XhoI fragments A, B, and C is indicated.

different approach. In vitro lac $Z$ fusions were made using the plasmid vector pDAH156, which carries a promoterless lac $Z$ gene. Given that $M$. xanthus DNA in pME100 most probably flanks the IS50 right of Tn5-lac at $\Omega$ MR 307, the $4.4 \mathrm{~kb}$ cloned fragment is likely to include the $\operatorname{ger} C$ gene promoter.

Plasmid pDAHI56 was designed to make in vitro lac $Z$ fusions and thus is particularly useful for localizing DNA regions which have the ability to promote gene expression. To localize the promoter within this region, pME 100 was digested with $X h o I$, which cuts twice in the cloned DNA and in the plasmid DNA. Restriction with Xhol thus yields four fragments (A, B, C, D), A, B and C being the ones carrying $M$. xanthus DNA. To test the ability of these three fragments to promote gene expression, we ligated Sall-cut pDAH156 with fragments A, B and C (see Methods and Fig. 2). Only in plasmids that had inserted fragment $\mathrm{C}$ could orientation with respect to the lac $Z$ gene be determined by restriction analysis. For fragments $\mathrm{A}$ and $\mathrm{B}$, several clones were used to make sure that at least one carried the fragment inserted in the correct orientation. The chimeric plasmids were separately transferred from $E$. coli to $M$. xanthus DK 1050. Integration of the plasmids by homologous recombination results in tandem duplication of those sequences common to the insert and the chromosome.

Transductants with plasmids carrying fragment A were not obtained. This may be attributed to the size of $M$. xanthus DNA in this particular insert being too small to allow homologous recombination.

Five $\mathrm{Km}^{\mathrm{R}}$ transformants carrying a plasmid with insert B were lysed with coliphage Pl and the chimeric plasmids were independently transduced into DK 1050. The incoming plasmid integrates into the chromosome by homologous recombination, duplicating in tandem fragment $\mathbf{B}$. Two alternative constructions are expected depending on the orientation of fragment $B$ with respect to the lac $Z$ gene in the chimeric plasmid (see Fig. 8). Individual $\mathrm{Km}^{\mathrm{R}}$ transductants were toothpicked onto nutrient and starvation agar plates containing $X-G a l$ and screened for expression of $\beta$-galactosidase. All the transductants obtained in one of the crosses were phenotypically $\mathrm{Lac}^{-}$as indicated by the absence of a colour reaction on both media. The other four lysates gave rise to transductants that expressed $\beta$-galactosidase on nutrient and starvation agar $\left(\mathrm{Lac}^{+}\right)$. Presumably these transductants correspond to the construction illustrated in Fig. 8(b). With regard to germination, both the $\mathrm{Lac}^{+}$ and the $\mathrm{Lac}^{-}$types showed the same defective behaviour as strain MR307.

Production of $\beta$-galactosidase by each class of transductants was measured throughout the $M$. xanthus life cycle. Those transductants classified as $\mathrm{Lac}^{-}$on plates containing X-Gal proved to be so when expression of the lac $Z$ gene was measured (see B1 fusion in Fig. 9). Fig. 9 also presents the profiles of $\beta$-galactosidase activity obtained for B2 fusion, a representative of the $\mathrm{Lac}^{+}$ phenotype. During vegetative growth, enzyme activity increased gradually from 6 units at early exponential growth to 45 units when the stationary phase was reached (Fig. 9a). Production of $\beta$-galactosidase during development is illustrated in Fig. $9(b)$. The level of enzyme activity for samples taken at $t=0$ was comparable to that found for late-exponential growth, when cells were spotted on CF agar plates. Enzyme production increased over vegetative levels during the first few hours, peaked at $24 \mathrm{~h}$ of development and then started decreasing, being particularly low late in development. The maximum level of enzyme production was reached at a time when microscopical observation revealed a majority of cells with spore morphology. $\beta$-Galactosidase activity during germination remained as low as for samples taken late in development (Fig. 9c).

The above results support the idea that there is a developmentally regulated promoter in or upstream of fragment $\mathrm{B}$. The fact that all the $\mathrm{Km}^{\mathrm{R}}$ transductants tested, regardless of their Lac phenotype, showed 


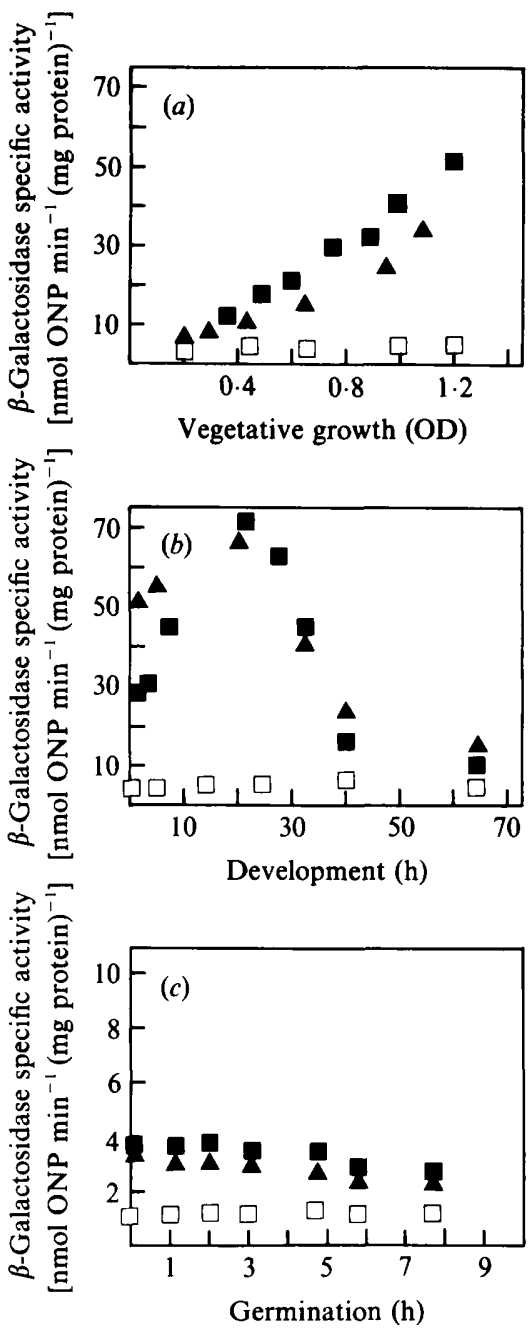

Fig. 9. Expression of $\beta$-galactosidase in B1 ( $\square)$, B2 ( $\square)$, and $\mathrm{Cl}(\boldsymbol{\Lambda})$ fusions during vegetative growth $(a)$, development $(b)$ and germination (c).

germination-defective behaviour is consistent with the location of the promoter upstream of fragment B.

Since fragment $C$ is located upstream of fragment $B$, we next measured expression of gene lac $Z$ when fragment $\mathrm{C}$ is inserted before the reporter gene. Identification of a chimeric plasmid carrying insert $\mathrm{C}$ in the correct orientation with respect to the lac $Z$ gene was possible by double restriction with $S a l / / X h o I$. Such a chimeric plasmid was transduced into DK1050 with selection for $\mathrm{Km}^{\mathbf{R}}$ (see Fig. 10), and the production of $\beta$ galactosidase and germination were assayed. The profiles of enzyme activity during cell growth, development and germination were very similar to those already presented for transductants carrying a tandem duplication of fragment $\mathrm{B}$ (see $\mathrm{Cl}$ fusion in Fig. 9). This result suggests that expression of $l a c Z$ in $\mathbf{B}$ fusions is dependent

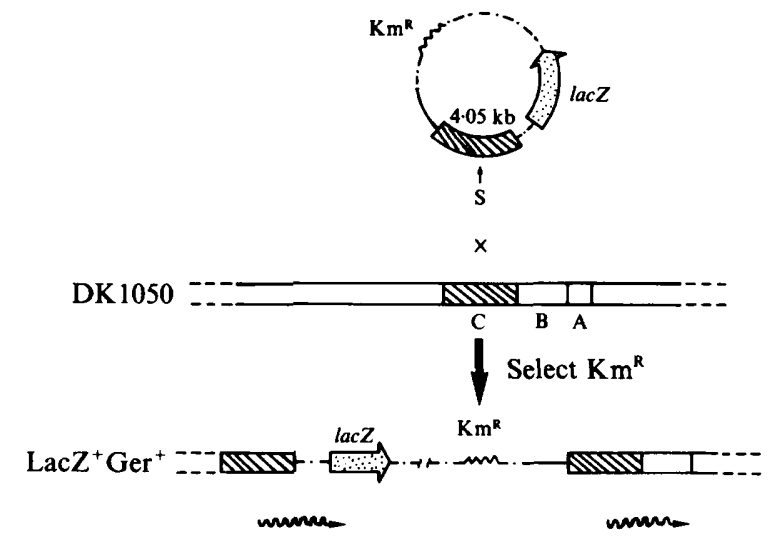

Fig. 10. Introduction into DK 1050 of a chimeric plasmid carrying the $X$ hoI fragment $\mathrm{C}$ from pME100 in the correct orientation to make a fusion. The plasmid was constructed following the procedure shown in Fig. 2. The relative location in DK 1050 of chromosomal DNA in $X h o l$ fragments A, B, and C is indicated. S, SaII.

on a promoter located in fragment C. Several transductants tested showed a wild-type germination behaviour, indicating that in the construction shown in Fig. 10 a complete gerC allele must have been restored. Taken together these data suggest that the promoter of gene gerC is located in fragment $\mathrm{C}$ and that the mutant phenotype of strain MR307 results from disruption of a gene differentially expressed during development. Since MR307 undergoes normal development, the affected gene might encode a structural spore component unnecessary for development but essential early after induction of germination. There is an obvious link between development and germination. In particular, the early events during germination are very likely to depend on characteristics gradually acquired during sporulation. We have already mentioned that MR307 is blocked early during germination, and this is consistent with the fact that the gene is developmentally regulated.

Molecular analysis of $\operatorname{ger} C$ and its gene products will provide information about the specific defect that causes this mutant phenotype. On the other hand, the lacZ reporter gene should provide an easy way to search for trans-acting regulatory elements controlling $\operatorname{gerC}$ and perhaps also other genes involved in germination.

We thank Maribel Carretero for technical assistance. We also thank D. A. Hodgson for providing plasmid strains. This work was supported by grant PB86-0416 from the Spanish Dirección General de Investigación Científica y Técnica.

\section{References}

AVERY, L. \& KaISER, D. (1983). In situ transposon replacement and isolation of a spontaneous tandem genetic duplication. Molecular and General Genetics 19, 99-109. 
Balsalobre, J. M., Ruiz-Vázquez R. M. \& Murillo, F. J. (1987). Light induction of gene expression in Myxococcus xanthus. Proceedings of the National Academy of Sciences of the United States of America 84, 2359-2362.

BretsCher, A. P. \& Kaiser, D. (1978). Nutrition of Myxococcus xanthus, a fruiting myxobacterium. Journal of Bacteriology 133, 763768.

Casadaban, M. J. \& Cohen, S. N. (1980). Analysis of gene control signals by DNA fusion and cloning in Escherichia coli. Journal of Molecular Biology 138, 179-207.

DWORKIN, M. \& KAISER, D. (1985). Cell interactions in myxobacterial growth and development. Science 230, 18-24.

Elías, M. \& Murillo, F. J. (1991). Induction of germination in Myxococcus xanthus fruiting body spores. Journal of General Microbiology 137, 381-388.

GILl, R. E., Cull, M. G. \& FLY, S. (1988). Genetic identification and cloning of a gene required for developmental cell interactions in Myxococcus xanthus. Journal of Bacteriology 170, 5279-5288.

Hagen, D. C., Bretscher, A. P. \& Kaiser, D. (1978). Synergism between morphogenetic mutants of Myxococcus xanthus. Developmental Biology 64, 284-296.

HodGKIN, J. \& KAISER, D. (1977). Cell-to-cell stimulation of movement in nonmotile mutants of Myxococcus. Proceedings of the National Academy of Sciences of the United States of America 74, 2938-2942.

KAISER, D. (1984). Genetics of myxobacteria. In Myxobacteria Development and Cell Interactions, pp. 163-184. Edited by E. Rosenberg. New York: Springer-Verlag.
KROOS, L. \& KaISER, D. (1984). Construction of Tn5-lac, a transposon that fuses lac $Z$ expression to exogenous promoters, and its introduction into Myxococcus xanthus. Proceedings of the National Academy of Sciences of the United States of America 81, 5816-5820.

Maniatis, T., Fritsch, E. F. \& SAMBroOK, J. (1982). Molecular Cloning: a Laboratory Manual. Cold Spring Harbor, NY: Cold Spring Harbor Laboratory.

ROSNER, J. L. (1972). Formation induction and curing of bacteriophage Pl lysogens. Virology 48, 679-689.

Ruiz-VÁzquez, R. M. \& Murillo, F. J. (1984). Abnormal motility and fruiting behavior of $M y$ xococcus xanthus bacteriophage-resistant strains induced by a clear-plaque mutant of bacteriophage Mx8. Journal of Bacteriology 160, 818-821.

ShIMKETS, L. J. (1987). Control of morphogenesis in myxobacteria. CRC Critical Reviews in Microbiology 14, 195-227.

Shimkets, L. J., Gill, R. E. \& KAISER, D. (1983). Developmental cell interactions in Myxococcus xanthus and the spoC locus. Proceedings of the National Academy of Sciences of the United States of America 80, 1406-1410.

Stephens, K. \& KaISER, D. (1987). Genetics of gliding motility in Myxococcus xanthus: molecular cloning of the $\mathrm{mgl}$ locus. Molecular and General Genetics 207, 256-266.

YeE, T. \& INOUYE, M. (1981). Reexamination of the genome size of myxobacteria, including the use of a new method for genome size analysis. Journal of Bacteriology 145, 1257-1265.

ZusmaN, D. R. (1984). Cell-cell interactions and development in Myxococcus xanthus. Quarterly Review of Biology 50, 119-138. 